\title{
EARLY MANAGEMENT OF NEUROPATHIC BLADDER IN SPINAL CORD INJURIES ${ }^{1}$
}

\author{
By J. Dermot O’FlynN, M.Ch., F.R.C.S.(Ed.), F.R.C.S.I. \\ National Medical Rehabilitation Centre of Ireland, Dun Laoghaire; Urological Department, \\ Meath Hospital, Dublin; Department of Surgery, Trinity College, Dublin
}

FollowiNG spinal cord injury the syndrome of spinal shock is reflected in the bladder by a state of atonicity. The smooth muscle of the bladder loses its normal tone and if cystometry is done at this stage no normal vesical contractions are discernible. This state is complicated by the fact that the external urethral sphincter (which is composed of striated muscle fibres, and which is usually closed) becomes paralysed, remains closed and cannot be relaxed. The bladder now has two peculiar disabilities-it cannot contract and empty itself, and its outlet is obstructed. Bladder tone and the ability to contract usually return in a period of days or a few weeks and vesical contractions can once again be detected on cystometry, but now the bladder may be subjected to very sudden and very violent rises of intravesical pressure, either due to uninhibited contractions of the vesical detrusor or participation in generalised aberrant reflux action. Despite the fact that the bladder does contract it does not necessarily empty satisfactorily as the external sphincter remains unrelaxed and the bladder cannot empty completely because its outlet is obstructed. The bladder's response to this situation is to hypertrophy, and the resulting raised intravesical pressure may enable it to overcome the external sphincter closure pressure-a small number of patients will establish apparently normal micturition. Most cases do not establish normal voiding and this will lead to complete or partial retention, and if this condition is untreated, urinary infection, reflux, stone formation, upper urinary tract back pressure and renal deterioration will occur.

The whole concept of treatment of neuropathic bladder following spinal cord injury (or any other neurological injury) is the anticipation and treatment of vesical outlet obstruction.

In general, it can be said that the higher and more complete the spinal lesion the greater the bladder disability, and the lower and more incomplete the lesion the less the bladder disability, but there are many exceptions to this and it is well known that the bladder disability may not reflect in any degree the level or extent of the neurological lesion.

The rapid deterioration of urinary tract function in spinal cord injury cases makes essential early admission to a rehabilitation unit and early urological assessment. If renal function can be preserved, then (apart from certain types of tetraplegia where respiratory complications predominate) the prognosis and life expectation of the average spinal cord injury case can be very good.

Retention of Urine and Urethral Catheterisation. Due to bladder atonicity and vesical outlet obstruction, retention of urine develops in 80 per cent

\footnotetext{
1 Abridged version of lecture at Special Aspects of Urology Symposium, University of Liverpool, September 1973.
} 
of all spinal cord injury cases and is best treated by either intermittent or continuous catheterisation.

Intermittent Catheterisation. This is the method of choice as the incidence of urinary infection is less if intermittent catheterisation is used. It can be done for prolonged periods of time without infection developing if it is done with rigid aseptic precautions and the patients are catheterised by skilled personnel (Guttmann \& Frankel, 1965; Walsh, 1965; Wilmot \& O'Flynn, 1967). The bladder should be emptied every six to eight hours using a small-calibre catheter (I6F). This method has the advantage that if the bladder resumes normal function, normal voiding may occur while the patient is awaiting catheterisation. It has the disadvantage that it cannot always be done for patients who are otherwise seriously ill, and it is very time-consuming for the medical or nursing personnel.

When infection occurs, the source appears to be the urethra (Stickler, Wilmot \& O'Flynn, I97I) and, if urethral infection can be demonstrated, cystopyelitis may be avoided by giving an appropriate antibiotic. Repeated or recurrent urinary infections may occur during intermittent catheterisation, and continuous urethral catheterisation may then be necessary.

Continuous Catheterisation. A No. I6 F. Foley catheter or a Gibbons catheter may be used for continuous catheterisation, the catheter being changed every seven to ten days, and the patient maintained on a high fluid intake. The advantage of this method is its ease of maintenance and it may be the only method possible in seriously injured, or ill, patients. It has the great disadvantage that urinary infection will occur in all cases so treated.

In an earlier study of I 66 consecutive cases admitted, I40 needed catheterisation, and of these, IOI were treated by continuous catheterisation and 39 by intermittent catheterisation only (O'Flynn, I968). Continuing experience has shown that intermittent catheterisation is very successful in lower and incomplete spinal cord lesions, while most complete and high-level lesions must be treated by continuous catheterisation.

Trial of Micturition. This may be done at about three months, or earlier if the patient shows rapid neurological recovery. Catheterisation is stopped and the patient's ability to void is observed. Some patients pass urine at once and continue to do so; others establish fairly normal micturition with the help of Urecholine (bethanechol chloride) or carbachol. Other cases have initial difficulty, but improve. Some get retention at once. Close observation is necessary at this time. Repeated abdominal palpation is important to find out if the bladder is being emptied satisfactorily and frequent residual urine estimations may be necessary. At this time also, a full urological assessment, which includes an intravenous pyelogram with post-micturition films and renal function studies, should be done to decide whether outlet obstruction is present and to determine the state of the upper urinary tract. A retrograde cystogram should be done to exclude reflux, and cystometry is necessary to assess bladder tonicity.

The onset of outlet obstruction can be quite insidious and upper urinary tract back pressure may develop without any other obvious systemic effects initially. In cases where the urinary stream appears to be poor and there is some doubt about the complete emptying of the bladder, an intravenous pyelogram should be done. This may show that apart from the fact that the bladder emptying is in- 
complete, ureterectasis and pyelectasis may be present, and necessitate reinsertion of the catheter and reassessment with a view to deciding what operative treatment for vesical outlet obstruction is necessary. Reflux may also appear insidiously, and even while the bladder drainage is apparently satisfactory on catheterisation. Cystometry is of limited value at this stage, but vesical atonicity can be easily diagnosed by its use, and if this is present, more prolonged catheter drainage and the delay of vesical outlet operations may be necessary.

Urinary Infection. Despite careful catheter technique, there is a high incidence of urinary infection and as many as 70 per cent of spinal cord injury cases may have urinary infection at some time during rehabilitation. In intermittently catheterised cases the source of infection is the urethra (Stickler, Wilmot \& O'Flynn, I97I). The onset of pyelocystitis can be prevented if the posterior urethra is swabbed for bacteria during catheterisation and an appropriate antibiotic given at once if organisms are present. In the continuously catheterised cases, where there is about Ioo per cent infection rate, the best prophylaxis is a high fluid intake, broad spectrum antibiotics being reserved for situations where there is systemic disturbance from infection.

It is impossible to sterilise the urine while a catheter is in situ. Occasionally a severe pyrexial attack, accompanied by prostration, shock and oliguria ('the flare-up') occurs and urgent antibiotic and supportive treatment is necessary. The most likely cause of this is urinary infection and obstruction. It is essential in every spinal cord injury unit that an antibiotics policy, monitored by the bacteriologist and clinicians, is followed, and only the recommended antibiotics used at any one time. If such a policy is not used, the development of urinary tract infections insensitive to all available antibiotics, is possible. Mild urinary infection in the catheterised patient should be treated by a high fluid intake only and the antibiotics reserved for the patient with systemic effects from the infection. The complications of urinary infection are stone formation and epididymitis, and in patients with outlet obstruction it can lead to rapid renal deterioration. It is vital that the urinary infection incidence should be kept as low as possible, but, despite this, infection is still a major hazard of spinal cord injuries and up to 60 per cent of cases may still be infected on discharge from a rehabilitation centre.

No two spinal cord injury cases behave in the same way, and the extent and level of the spinal lesion gives only a rough indication of what the eventual urological disability may be. Occasionally, high and complete cervical lesions void spontaneously and continue to do so, while other less severely handicapped patients develop serious urological disorders which demand the constant vigilance and care of the rehabilitation team. No form of treatment may be continuously satisfactory and rigid adherence to a management plan is not always possible. Not infrequently, a patient who has been treated initially by intermittent catheterisation may need continuous catheterisation, and the reverse may also be necessary.

About 30 per cent of all cases admitted to a spinal cord injury unit will need some operation, either external sphincterotomy or transurethral resection of the vesical neck, or both, to relieve outlet obstruction, and it is very important that the urinary tract function should be satisfactorily preserved and that infection should be well controlled until such time as the vesical outlet obstruction is dealt with. This can be satisfactorily achieved in most cases by the type of management outlined here. 
SUMMARY

The e rly management of neuropathic bladder in spinal cord injuries is outlined, an 1 experience with intermittent and continuous catheterisation, and urinary infe tion, is discussed.

\section{RÉSUMÉ}

Le traitement de début de la vessie neurogène dans l'atteinte médullaire est souligné. L'expérience avec le sondage intermittent, le drainage par sonde à demeure et l'infection urinaire est discuté.

\section{ZUSAMMENFASSUNG}

Die Frühbehandlung der neuropathischen Blase wird beschrieben und die Erfahrungen mit intermittierender Katheterisation und Danerkatheter sowohl mit der Infektion werden diskutiert.

\section{REFERENCES}

Guttmann, L. \& Frankel, H. (1965). Int. F. Paraplegia, 4, 63.

O'FLYNN, J. D. (I968). Unpublished.

Stickler, D. J., Wilmot, C. B. \& O’Flynn, J. D. (I97I). Int. F. Paraplegia, 8, 243.

WALSH, J. (I965). Personal communication.

Wilmot, C. B. \& O’FlynN, J. D. (1967). Urology Digest, 6, I7. 